\title{
EFFECT OF COGNITIVE RESTRUCTURING TECHNIQUE ON BULLYING BEHAVIOUR OF SECONDARY SCHOOL STUDENTS IN ANAMBRA STATE, NIGERIA
}

\author{
Ekwelundu, Chinyere Anthoniai; \\ Nnamdi J. Obikeze; \\ Obi, Ifeoma \\ Department of Educational Foundations, \\ Chukwuemeka Odumegwu Ojukwu University, \\ Igbariam Campus, \\ Nigeria
}

\section{Abstract:}

Bullying behaviour among students has become a serious social problem in secondary schools. It is an ugly development that has given much concern to parents, teachers, counsellors, and stakeholders in the education industry. This study examined the effect of the cognitive restructuring technique on bullying behaviour of secondary school students in Anambra State. Two research questions guided the study, while two null hypotheses were tested at a .05 level of significance. The study adopted a quasiexperimental, non-equivalent pre-test and post-test, control group design. The study population was 586 which comprised 354 males and 232 females SSII student bullies in the 47 co-educational public secondary schools in Awka Education Zone. A sample of 94 student bullies made up 54 males and 40 females were purposively drawn from three schools with the highest number of bullies and used for the study. Two schools were as experimental groups for cognitive restructuring and assertiveness training while the remaining one was for the control group. Students Bullying Behaviour Identification Scale (SBBIS) and Students Bullying Behaviour Questionnaire (SBBQ) were adapted as instruments for data collection. The instruments were subjected to face and content validation. The reliability of the instruments was established using Cronbach Alpha and with coefficients of 0.88 for SBBQ and 0.96 for SBBIS. SBBIS was administered two weeks before the commencement of the treatment aimed at identifying and screening bullies while SBBQ was used for the pretesting and post-testing for the three groups. Mean was used to answer research questions, while the null hypotheses were tested using Analysis of Co-Variance (ANCOVA). The findings of the study revealed that the Cognitive Restructuring technique was effective in reducing bullying behaviours of secondary school students. The findings equally indicated that the difference in the effectiveness of the Cognitive Restructuring technique on bullying behaviours of male and female

\footnotetext{
'Correspondence: email ifeanyichukwua@gmail.com
} 
secondary school students was not significant. Based on the findings of the study it was recommended among others that guidance counsellors through school authorities should plan programme of intervention based on principles of cognitive restructuring technique for more enlightenment for students on bullying behaviour.

Keywords: effect, cognitive restructuring technique, bullying behaviour, secondary school, students

\section{Introduction}

School institutions are very relevant for children in Nigeria and throughout the world as a way of socialisation and learning. It serves as a foundation for empowering and certifying the need for human growth. The school environment, on the other hand, is required to mould a student's learning behaviour by making it secure, pleasant, encouraging to learn, and dignified for the children so that they can grow and develop optimally. Students have access to fresh, socially created, and systemized information through education. However, in reality, only a few students may be able to mingle or participate with their peers amicably. Some may experience some level of difficulty relating with their friends and could engage in maladaptive behaviours such as bullying that have the tendency to limit the teachers' ability in creating a constructing learning environment.

A positive learning environment is required for the process of implementing effective education. School bullying is one of the many difficulties that can arise in the school setting. As a result, because bullying is one of the difficulties linked with schooling, it is a source of worry for counsellors, researchers, parents, school authorities, and other stakeholders in education, because a school institution is primarily designed for teaching and learning. Meanwhile, school bullying is not a new phenomenon; in fact, there has been an increase in social and scientific awareness about it in recent years. Bullying, as Thornberg (2010) noted, is more than just a game for children; it is has become a scary experience for many school children.

Bullying has been difficult to define since no single description can encompass all characteristics of bullying. However, Olweus in Mbadugha, Omotola, and Chukwujama (2019) defined bullying as when an individual is repeatedly and over time exposed to negative physical, verbal, or relational actions on the part of one or more people as a result of power imbalances with the intention of causing harm to the victims. Similarly, Al-Raqqad, Al-Raqqad, Al-Bourini, Al Talahin and Aranki (2017) defined school bullying as a kind of violence that damages others that occurs at school or during other events when a student or group of students utilises their strength to injure other people or groups. Gladden, Vivolo-Kantor, Hamburger, and Lumpkin (2014) added that bullying referred to an unwanted aggressive behaviours enacted intentionally over-time by an individual or group using some form of power to cause physical and /or psychological harm to another individual or group in a shared social context. 
Bullying in the context of this study is be defined as an interpersonal violence in which power and aggression are used to cause distress to a vulnerable person. More so, school bullying behaviours among students are repeatedly aggressive acts by one or more students against another student with difference in strength between the perpetrator and the victim with the intention of inflicting disturbing physical, verbal or cyber harm on the victim.

There are many reported cases of prevalence of bullying by researchers. In western countries as reviewed by Juvonen and Graham (2014), concluded that approximately 20$25 \%$ of youths are directly involved in bullying as perpetrators, victims, or both. Menesini and Salmivalli (2017) added that 4-9\% of youths frequently engage in bullying behaviour and $9-25 \%$ of school age children are bullied. Also, in recent meta-analysis of bullying and cyberbullying prevalence across contexts, Modecki, Minchin, Harbaugh, Guerra, and Renions (2014) reported that a mean prevalence of $35 \%$ for traditional bullying of both perpetration and victimization roles and $15 \%$ for cyberbullying involvement.

In Nigeria, the prevalent rate of school bullying has not been fully established. Omoteso (2011) in his study in Ile-Ife reported that $88.1 \%$ of the participants reported being bullied, $33.1 \%$ were bullies and $64.7 \%$ had been involved in relational bullying whereas retaliation for being bullied in the past was $51.2 \%$. The study also revealed that younger students in junior secondary schools took part in bullying more than older students in senior secondary schools. Likewise, Owuamanam and Makinwa (2015) in their study reported that 600 secondary school students in Ondo State with $27.5 \%$ of the students had been bullied, and $42.3 \%$ of the students had bullied other students.

However, based on school type, Alex-Hart, Okagua, and Opara, (2015) reported that bullying was more prevalent in all-boys $(90.8 \%)$ and all-girls $(82.9 \%)$ school than in mixed schools. This goes on to show that gender is a factor that plays a role in both male and female tendency to bullying behaviour. Males are historically believed to be generally more prone to bullying than females from early age (Jacklin, \& Marccoby, 2010). More so, boys perform visible acts of bullying more than girls, in order to mark their status among their peers, as a result, boys are more often exposed to disciplinary actions such as being reported to the police (Burcer, 2013).

In addition Ugwu (2012) noted that gender goes beyond biological sex to include a person's understanding of meaning to one's own life of being males or females. In support of this, Halpern-Flesher (2014) stated that qualities such as assertiveness, strength, independence, bravely, rationality and dominance are attributed to male gender while nurturing, warmth, gentility, emotional and sensitivity attribute to female gender. Therefore boys are more likely to physical bullying such as pushing, kicking, slapping, and verbal threats while girls make use of indirect forms such as rumour spreading or gossiping, social ostracism.

School bullying in recent times is becoming a threat that no school can afford to dismiss with the wave of the hand. In Nigeria, the incidence of bullying occurs daily in secondary schools. It is a worrisome practice in schools because it infringes on the child's right to human dignity, privacy, freedom and security. In Anambra State, secondary 
school students experience an increase in the rate of repeated acts of disturbances among them. On daily basis, there are a lot of media headlines on students bullying their fellow students on several occasions through physical, verbal or cyber means that lead to unhealthy action by the victims in order to escape the seemingly endless negative relational behaviours. It is difficult to discover a secondary school in Anambra State today where bullying does not exist.

According to Nwankwo and Unachukwu in Ettue (2012), in Anambra State, $76.81 \%$ and $92.50 \%$ of primary and post-primary school teachers respectively identified bullying as a disruptive disorder in school. The school managements have outlined penal measures on bullying behaviour in schools. In most cases, such students are expelled from the school and sent into the wider society. Expulsion of students who engaged in bullying in the school setting is not an ideal way of reducing students' bullying behaviour in secondary schools in Anambra State. Although bullying may not be eliminated completely, a successful anti-bullying programmes or interventions have the ability to change the school climate and make the school a more enjoyable and comfortable place to learn. The study of Badejo and Ubangha in Ettu (2012) revealed that both bullies and victims of bullying can be successfully helped with a treatment package based on the principles of cognitive restructuring.

Cognitive restructuring was originally developed by Beck in the 1960s and aims at removing one's "faulty thinking" and irrational counter-factual beliefs with more accurate and beneficial ones. Therefore, it is a technique that can be used in reducing bullying behaviour. It is a psychotherapeutic process of learning to identify irrational or maladaptive thoughts. According to Chujor and Kennedy (2014), cognitive restructuring is a process by which the individual is made to avoid crooked and irrational thinking, guiding the individual to think straight. Cognitive restructuring is a counselling technique used to assist an individual to reduce negative emotional reactions. The emphasis during therapy is to help a client modify his distorted perception of the world caused by negative mind set.

Cognitive restructuring aim at modifying distorted thinking patterns and negative self-talks that arise from internalized wrong belief (Egenti \& Ebenebe, 2018). The technique restructures the already structured irrational thoughts, beliefs and philosophies, which an individual has already acquired by redressing and changing them at the mental level of the person concerned, to ensure his happiness and efficiency at school or workplace (Onyije \& Ojedapo, 2010). Cognitive restructuring operationally is a behaviour modification technique that is based on teaching a client how to reduce negative emotional reactions by getting him to interpret situations with greater accuracy. Specifically, the problem is to get the individual or client to avoid crooked thinking and think straight.

The cognitive restructuring therapists try to teach people to think in a more rational and constructive way. It involves teaching students or clients to reduce their negative emotional reactions by getting them to interpret situations with greater accuracy and avoid distorted thinking, but to think rightly. The major task facing the therapist 
engaged in cognitive restructuring is how to modify the student's distorted perception of the world. As Chujor and Kennedy (2014) noted, an accurate interpretation of the realities of life can arise from the nature of the mental set which a person brings to his experience. If the dominant disposition is negative, reaction to human events will also follow such a line. The opposite is the case if the disposition is positive. It is assumed by therapists that one's interpretation of reality determines his emotional responses to it.

In a secondary school setting especially in Anambra State, bullying behaviour among male and female students has reached alarming stage in which teachers and principals have used different kinds of punitive measures such as corporal punishment, rustication and expulsion from school and so many other types of punishment in order to see if the students can reduce their level of bullying behaviour. All the measures put in place seems not to be effective because it does not restructure the faulty thinking of these students. Despite numerous efforts made by previous researchers in finding a lasting solution to the problem of bullying behaviour among secondary school students, the problem no doubt still poses a serious challenge to guidance counsellors and other allied professionals. For example, a good number of researchers like Isiyaku (2016) and Sudha (2019) have investigated the effect and effectiveness of different psychological and social counselling techniques on bullying behaviour among secondary school students, the problem still persists and remains a source of worry and concern to many researchers. Though a good number of studies have been carried out in this regard, not much has been done empirically to investigate the effect of cognitive restructuring on male and female secondary school students in Anambra state. This has led to a gap observed in literature which has necessitated this study that sought to determine the effect of cognitive restructuring and assertiveness training techniques on bullying behaviour among secondary school students in Awka Education Zone of Anambra State.

\section{Purpose of the Study}

The main purpose of this study was to examine the effect of cognitive restructuring on bullying behaviour of male and female secondary school students in Awka Education Zone. Specifically, the study sought to:

1) Determine the effect of cognitive restructuring technique on bullying behaviour among secondary school students in Awka Education Zone.

2) Find out the difference in the effectiveness of Cognitive Restructuring technique on bullying behaviour of male and female secondary school students in Awka Education Zone.

\subsection{Significance of the Study}

The findings of this study would be of both theoretical and practical significance. The study has some theoretical significance for cognitive behavioural theory by Beck 1960s. This, theory aims at explaining human behaviour in terms of the internal processes used by the individual for increasing the understanding of his world. Such understanding 
increases the individual's true freedom and allows more opportunity for personal growth. Applying this theory to bullies would make them reconstruct their cognition to adjust well in their environment.

Practically, this study would be of great significance to students, guidancecounsellors, teachers, non-governmental organizations (NGOS), Ministry of Education, and future researchers. This is informed by the fact that any study that exposes the efficacy and effectiveness of the application of cognitive restructuring technique would invariably equip experts in the field with requisite skills and knowledge to maximally utilize them in reducing bullying behaviours. It would also serve as a reference data for counselling programme on how to reduce bullying behaviour of the victim students in order to enhance their academic performance and feel safe.

\subsection{Research Questions}

The following research questions guided this study:

1) What is the effect of cognitive restructuring technique on bullying behaviour among secondary school students in Awka Education Zone when compared with those exposed to conventional counselling using their pre-test and post- test mean scores?

2) What is the difference in the effectiveness of Cognitive Restructuring technique on bullying behaviour of male and female secondary school students in Awka Education Zone when compared using their pre-test and post-test mean scores?

\subsection{Null Hypotheses}

The following null hypotheses were tested at .05 statistical level of significance:

1) The effect of Cognitive Restructuring technique on bullying behaviour of secondary school students in Awka Education Zone when compared with those exposed to conventional counselling using their pre-test and post-test mean scores is not significant.

2) There is no significant difference in the effectiveness of Cognitive Restructuring techniques on bullying behaviours of male and female secondary school students in Awka Education Zone when compared using their pre-test and post-test mean scores.

\section{Materials and Methods}

\subsection{Research Design}

This study is a non-randomized pre-test, post-test, control group quasi-experimental research. The study involved two treatment conditions (Experimental and Control group), each comprising of students that showed a tendency to bullying. 


\subsection{Research Setting}

The study was conducted in Awka Education Zone of Anambra State, Nigeria. The area was chosen for the study based on observation by researcher having recorded high rate of bullying behaviour among secondary school students irrespective of the punitive measures taken to stop them from being bullying.

\subsection{Participants}

The sample of the study comprised 94 students selected from a population of 586 students. The population comprised all the students identified with bullying tendency. The selection was based on the level of their inclination to bullying indicated by their pretest scores obtained through administration of the questionnaire.

\subsection{Instrument for Data Collection}

The two instruments for data collection were the Students Bullying Behaviour Identification Scale (SBBIS) and the Students Bullying Behaviour Questionnaire (SBBQ). Students bullying behaviour Identification Scale (SBBIS) was developed by Usman 2019 and adapted by the researcher. It was designed for the purpose of identifying the students who are bullies. It has four-point rating scale with response options of Strongly agree (SA), Agree (A), Disagree (D), and strongly disagree (SD). The second instrument used in the study titled "Students Bullying Behaviour Questionnaire" (SBBQ) was developed by Isiyaku (2016). It was adapted by the researcher. The items were placed on 4-point scale of Strongly Agree (SA), Agree (A), Disagree (D) and Strongly disagree (SD). Using Cronbach Alpha, the reliability coefficient of 0.96 for SBBIS was obtained.

\subsection{Experimental Procedure}

The researcher obtained the approval of the schools' management for carrying on with the research through a consent letter that was given to the management. The experimental training sessions then took place at the two schools chosen for the study. The researcher, with the assistance of the guidance counsellors in the schools as research assistants, conducted a training programme which was held for eight weeks for both the treatment and control group. The treatment sessions were carried out in the school's counselling centres. The day and time for each group's training was established and maintained throughout the treatment.

Each training session lasted for 50 minutes using the counselling scheduled periods as specified by the schools. The participants in the experimental groups were trained on Socio-cognitive Skills while those in the control group were received the usual conventional group counselling. Each of the groups received training for eight weeks. After the eight weeks of treatments, the Students bullying behaviour Identification Scale (SBBIS) was re-administered on all the participants in both the experimental and control groups. The scores obtained were stared as the post-test. The post-test scores along with the earlier elicited pre-test scores were then collated and analysed. 


\subsection{Method of Data Analysis}

The completed instruments were scored following the scoring instructions provided in the Students bullying behaviour Identification Scale (SBBIS) manual. The research question was answered using statistical Mean while the null hypotheses were tested using the Analysis of Co-variance (ANCOVA).

\section{Results}

The data analysed are presented as follows:

Research Question 1: What is the effect of the Cognitive Restructuring technique on bullying behaviour of secondary school students when compared with those exposed to conventional counselling using their pre-test and post-test mean scores?

Table 1: Pre-test and Post-test Bullying Behaviour Mean Scores of Students Exposed to Cognitive Restructuring Technique and those Exposed to Conventional Counselling (Norm=70.00)

\begin{tabular}{lccccc}
\hline Source of variation & $\mathbf{N}$ & Pre-test Mean & Post-test Mean & Lost Mean & Remark \\
\hline Cognitive Restructuring Technique & 31 & 80.77 & 64.39 & 16.38 & Effective \\
Control & 35 & 80.63 & 78.09 & 2.54 & \\
\hline
\end{tabular}

Result presented in Table 1 revealed that the pre-test mean scores of the students exposed to Cognitive Restructuring is 80.77 while the post-test mean score is 64.39 , with a lost mean reduction of 16.38; while those in the control group who received conventional counselling have pre-test mean score of 80.63 and post-test mean score of 78.09 with reduction in mean of 2.54 . Therefore, with a post-test mean score of 64.39 which is below the norm 70.00, Cognitive Restructuring technique was effective in reducing bullying behaviour of secondary school students.

Research Question 2: What is the difference in the effectiveness of Cognitive Restructuring technique on bullying behaviour of male and female secondary school students when compared using their pre-test and post-test mean scores?

Table 4: Pre-test and Post-test Bullying Behaviour Mean Scores of Male and Female Students Exposed to Cognitive Restructuring Technique

\begin{tabular}{lccccc}
\hline Source of variation & $\mathbf{N}$ & Pre-test Mean & Post-test Mean & Reduced Mean & Remark \\
\hline Male & 17 & 81.41 & 66.29 & 15.12 & \\
Female & 14 & 80.36 & 62.93 & 17.43 & More effective \\
\hline
\end{tabular}

The result displayed in Table 2 showed that the pre-test mean scores of male students exposed to Cognitive Restructuring is 81.41 while the post-test mean score is 66.29 , with a mean reduction of 15.12; while the pre-test mean of female students who were also Cognitive Restructuring have pre-test mean score of 80.36 and post-test mean score of 
62.93 with reduction in mean of 17.43 . Therefore, with a mean reduction score of female students being higher than the mean reduction score of male students, Cognitive Restructuring technique was more effective in reducing bullying behaviour of female secondary school students.

\subsection{Testing the Null Hypotheses}

Null Hypothesis 1: The effect of Cognitive Restructuring technique on bullying behaviour of secondary school students when compared to those in the control group using their pre-test and post-test mean scores is not significant.

Table 3: ANCOVA on the Bullying Behaviour Post-Test Mean Scores of Students Exposed to Cognitive Restructuring Technique and those who Received Conventional Counselling

\begin{tabular}{lcccccc}
\hline Source of variation & SS & df & MS & Cal. F & Pvalue & P $\leq . \mathbf{0 5}$ \\
\hline Corrected Model & 3658.664 & 2 & 1829.332 & 145.090 & & \\
Intercept & 64.820 & 1 & 64.820 & 5.141 & & \\
Pretest & 573.777 & 1 & 573.777 & 45.508 & & \\
Treatment_Model & 3127.525 & 2 & 3127.525 & 248.053 & .001 & $\mathrm{~S}$ \\
Error & 794.321 & 63 & 12.608 & & & \\
Total & 343293.000 & 66 & & & & \\
Corrected Total & 4452.985 & 65 & & & & \\
\hline
\end{tabular}

Result displayed in Table 3 revealed that at .05 level of significance, $2 \mathrm{df}$ numerator and $65 \mathrm{df}$ denominator, the calculated F-ratio is 248.053 while the p-value is .001. Since the Pvalue was less than the required .05 significance level, the null hypothesis is rejected. Therefore, the effect of Cognitive Restructuring technique on bullying behaviour of secondary school students when compared to those in the control group using their pretest and post-test mean scores is significant.

Null Hypothesis 2: There is no significant difference in the effectiveness of Cognitive Restructuring techniques on bullying behaviours of male and female secondary school students.

Table 4: ANCOVA on the Post-test Bullying Behaviour Mean Scores of Male and Female Students Exposed to Cognitive Restructuring Technique

\begin{tabular}{lcccccc}
\hline Source of variation & SS & df & MS & Cal. F & Pvalue & P $\leq .05$ \\
\hline Corrected Model & 190.511 & 2 & 95.255 & & & \\
Intercept & 100.122 & 1 & 100.122 & & & \\
Pretest & 103.549 & 1 & 103.549 & & & \\
Gender & 65.536 & 1 & 65.536 & 3.999 & .055 & NS \\
Error & 458.909 & 28 & 16.390 & & & \\
Total & 130716.000 & 31 & & & & \\
Corrected Total & 649.419 & 30 & & & & \\
\hline
\end{tabular}


Table 4 showed that at .05 level of significance, $1 \mathrm{df}$ numerator and $30 \mathrm{df}$ denominator, the calculated F-ratio is 3.999 while the p-value is .055 . Since the p-value is more than the required .05 significance level, the null hypothesis is accepted. Therefore, there is no significant difference in the effectiveness of Cognitive Restructuring techniques on bullying behaviours of male and female secondary school students.

\section{Discussions}

Findings of this study were discussed as follows:

\subsection{Effect of Cognitive Restructuring as on Bullying Behaviour among Secondary School Students}

The findings of this study as shown in Table 1 revealed that the pre-test mean scores of the students exposed to Cognitive Restructuring is 80.77 while the post-test mean score is 64.39 , with a lost mean reduction of 16.38; while those in the control group who received conventional counselling had pre-test mean score of 80.63 and post-test mean score of 78.09 with reduction in mean of 2.54. Therefore, with a post-test mean score of 64.39 which is below the norm 70.00, Cognitive Restructuring technique was effective in reducing bullying behaviour of secondary school students. This implies that cognitive restructuring technique is effective in improving positive behaviour among the students. The finding of the study is consistent with Dungurawa and Ibrahim (2021) whose finding revealed that cognitive restructuring counselling technique was effective in reducing bullying behaviour among students. Similarly, the findings of Nwokolo, Anyamene, and Nzerem (2020), and Agu (2014) reported that cognitive restructuring helped to reduced bullying behaviour of students.

This difference in mean scores was further subjected to statistical testing using ANCOVA. The result from the null hypothesis 1 indicated in Table 6 revealed that the effect of Cognitive Restructuring technique on bullying behaviour of secondary school students when compared to those in the control group using their pre-test and post-test mean scores is significant. This means that secondary school bullies treated with cognitive restructuring benefitted more than those in conventional group which might be due to thought changing patterns, underlying beliefs after the treatment. Furthermore, the treatment might have helped the participants in this group identify and dispute their negative self-perception and become more realistic in thinking. Since participants might have been amazed how their thought affects their feelings and actions and as such it affected their bullying acts so much within the few weeks. Agu (2014) outcome of treatment conditions revealed; that that there was significant difference in the reduction of bullying behaviour of participants exposed to cognitive restructuring technique and those in control group. The work of Agu affirmed that cognitive restructuring is effective in curbing bullying behaviour of students. 


\subsection{Difference in the Effectiveness of Cognitive Restructuring on Bullying of Male and Female Secondary School Students}

Findings of the study as displayed in Table 4 revealed that the pre-test mean scores of male students exposed to Cognitive Restructuring is 81.41 while the post-test mean score is 66.29, with a mean reduction of 15.12; while the pre-test mean of female students who were also Cognitive Restructuring have pre-test mean score of 80.36 and post-test mean score of 62.93 with reduction in mean of 17.43. However, with a mean reduction score of female students being higher than the mean reduction score of male students, Cognitive Restructuring technique is slight more effective in reducing bullying behaviour of female secondary school students. This suggests that female students benefited more from cognitive restructuring technique than male students did.

The findings further revealed as indicated in Table 9 that the difference in the effectiveness of cognitive restructuring on bullying behaviour male and female secondary school students is not significant. This implies that the treatment using cognitive restructuring technique has similar effects on both male and female secondary school students. Also the technique is not gender sensitive. This finding is in agreement with Dungurawa and Ibrahim (2021), whose study investigated the effect of cognitive restructuring on bullying behaviour among students and indicated no significant difference was observed between male and female respondents. Similarly in vain, Agu (2014) who carried out a study on effect of cognitive restructuring strategy on bullying among primary school pupils observed that gender as a factor in the study had no significant effect on the mean bullying adjustment of pupils with bullying behaviour. This finding was perhaps surprising to the researcher considering the fact that male and female are known to differ in personality characteristics, both biologically and in gender role socialisation. The reason for this could be attributed to the notion that students were almost on the same age level thereby making it possible to have similar mental abilities during the treatment period irrespective of gender.

Meanwhile, the researcher had expected a significant gender difference in favour of the male participants, the reason being that males are assumed to possess higher mental abilities, greater physical strength, and a positive attitude to bullying than their female counterparts. However, the results of this study voided the assumption and are in agreement that gender differences in response to the cognitive restructuring treatment are non-significant. The findings of the current study thereby affirm that both male and female secondary school students have the opportunity to overcome their bullying behaviour through cognitive restructuring training as indicated has no gender dimension, since its effect cut across genders having near matching effects on both the male and female participants.

\subsection{Conclusions}

Based on the findings of this study, the following conclusions are made:

This study provided evidence that cognitive restructuring was effective in reducing bullying behaviour among secondary school students. There is no significant 
difference in the effectiveness of Cognitive Restructuring techniques on bullying behaviours of male and female secondary school students.

\subsection{Recommendations}

Based on the findings of this study, the following recommendations are made:

1) Cognitive restructuring is an effective therapeutic technique in reducing bullying behaviours among secondary school students. Therefore, practicing counsellors working in secondary schools should make use of the technique in modifying bullying behaviour.

2) Since there was no significant gender difference in the effectiveness of the technique, gender should not be seen as a factor to be considered by the school guidance counsellor during behaviour modification treatment of bullies in schools.

\section{Acknowledgements}

The authors acknowledge that there is no involvement of a funding body or organization in the work.

\section{Conflict of Interest Statement}

The authors hereby declare that they have no affiliations with or involvement in any organization with any financial interest or non-financial interest in the subject discussed in this manuscript.

\section{About the Authors}

Chinyere Anthonia Ekwelundu is a $\mathrm{PhD}$ research Scholar in the Department of Educational Foundations, Chukwuemeka Odumegwu Ojukwu University, Igbariam Campus. She is a passionate and a practicing Guidance Counsellor with years of experience in counselling at the secondary school level.

Nnamdi J. Obikeze is a Professor in the Department of Educational Foundations, Chukwuemeka Odumegwu Ojukwu University, Igbariam Campus, Anambra State, Nigeria. He teaches Counseling courses as well as supervises graduate and undergraduate students in the field of research in education and guidance and counseling.

Ifeoma Obi is a Professor in the Department of Educational Foundations, Chukwuemeka Odumegwu Ojukwu University, Igbariam Campus, Anambra State, Nigeria. He teaches courses in the field of education as well as supervises graduate and undergraduate students in the field of research in education and guidance and counseling. 


\section{References}

Al-Raqqad, H.K., Al-Bourini, E.S., Al Talahin, F.M. \& Aranki, R.M.E. (2017). The impact of school bullying on students' academic achievement from teachers point of view. International Education Studies; 10(6), 44-50. ISSN 1913-9020 E-ISSN 1913-9039

Alex-Hart, B.A., Okagua, J., \& Opara, P.I. (2015).Prevalence of bullying in secondary schools in Port Harcourt. Int J Adolesc Med Health. 27(4), 391-6.

Chujor, J., \& Kennedy, M. C. (2014). Effects of counselling in curbing persistent lateness to school. International journal of innovative research and development, 3(4), 472-480.

Egenti, U. P., \& Ebenebe, R. C. (2018). Effects of cognitive restructuring on social adjustment of maladjusted in-school adolescence in secondary schools. Journal of Emerging Trends in Educational Research and Policy Studies (JETERAPS), 9(1), 29-33

Ettu, T.U. (2012). Assessment and management of bullying behaviour among senior secondary school students in Owerri, Nigeria. An unpublished thesis submitted to the school of Post Graduate Studies, University of Lagos.

Gladden, R.M., Vivolo-Kantor, A.M., Hamburger, M.E., \& Lumpkin, C.D. (2014). Bullying surveillance among youths: Uniform definitions for public health and recommended data elements, version 1.0. Atlanta, GA: Centres for disease control and prevention and U.S. Department of Education.

Halpern-Flesher, B., Kropp, R., \& Boyer, C. (2014). Adolescents' self-efficacy to communicate about sex: Its role in condom attitudes commitment and use. Adolescence, 39, 443-456.

Isiyaku, L. (2016). Effects of self-management and social skills counselling techniques on bullying behaviour among secondary school students in Katsina state, Nigeria. An Unpublished Thesis, Ahmadu Bello University, Zaria, Nigeria.

Juvonen, J., \& Graham, S. (2014). Bullying in schools: The power of bullies and the plight of victims. Annual Review of Psychology, 65, 159-185

Mbadugha, C.J., Omotola, N.J., \& Chukwujama, N.A. (2019). Bullying Behaviour among children and adolescents: The psychiatric-mental Health perspective. International Journal of Health Sciences \& Research, 9(9), 224-233. ISSN: 2249-9571.

Menesini, E., \& Salmivalli, C. (2017). Bullying in schools: The state of knowledge and effective interventions. Psychology, Health and Medicine, 22(1) 240-253. http://dx.doi.org/10.1080/13548506.2017.1279740.

Omotoso, B.A. (2010). Bullying behaviour, its associated factors and psychological effects. The Journal of International Social Research, 3(10), 508.

Owuamanam, D., \& Makinwa, V. I. (2015). Prevalence of bullying among secondary school students in Ondo State, Nigeria. European Scientific Journal, 11 (20), 326-333.

Modecki, K. L., Minchin, J., Harbaugh, A.G., Guerra, N.G., \& Runions, K.C. (2014). Bullying prevalence across contexts: A meta-analysis measuring cyber and traditional bullying. Journal of Adolescent Health, 55, 602-611. 10.1016/jadohealth.2014.06.007. 
Nwokolo, C. N., Anyamene, A. N., \& Efobi, A. C. (2011). Incidence of bullying among secondary school students in Anambra State, Nigeria: Implication for counselling. International Journal of Research in Counselling and Sports Science, IJORECS, 2(1), 106116.

Onyije, A.C., \& Ojedapo, D.O. (2010). Guidance and counselling services for achieving skills development in Nigerian secondary school system: The problems. Journal of Technical Education Research and Development, 3(1), 49-56.

Sudha, R. (2019). Group therapy, psychodrama, assertiveness training and counselling for bullying among middle school students in India. Iconic Research and Engineering Journals, 3(1), 206-220. ISSN: 2456-8880

Thornberg, R. (2010). Victimizing of bully: A grounded theory. Paper Presented at the Conference of European Educational Research Association.

Ugwu, C.J., \& Olatunbosun, I. (2016). Effect of cognitive behaviour therapy on reducing bullying on secondary school students in Ikwerre Local Government Area of River State, Nigeria. The Counsellor, 35(1\&2), 174-183.

Ugwu, T. (2012). Emotional maturity and adjustment in children. Journal of Interpersonal 2 (20) 221-231 
Creative Commons licensing terms

Author(s) will retain the copyright of their published articles agreeing that a Creative Commons Attribution 4.0 International License (CC BY 4.0) terms will be applied to their work. Under the terms of this license, no permission is required from the author(s) or publisher for members of the community to copy, distribute, transmit or adapt the article content, providing a proper, prominent and unambiguous attribution to the authors in a manner that makes clear that the materials are being reused under permission of a Creative Commons License. Views, opinions and conclusions expressed in this research article are views, opinions and conclusions of the author(s). Open Access Publishing Group and European Journal of Education Studies shall not be responsible or answerable for any loss, damage or liability caused in relation to/arising out of conflicts of interest, copyright violations and inappropriate or inaccurate use of any kind content related or integrated into the research work. All the published works are meeting the Open Access Publishing requirements and can be freely accessed, shared, modified, distributed and used in educational, commercial and non-commercial purposes under a Creative Commons Attribution 4.0 International License (CC BY 4.0). 